\title{
Occupational health risks associated with the use of germicides in health care
}

\author{
David J. Weber MD, MPH ${ }^{a, b, c, *}$, Stephanie A. Consoli RN ${ }^{b}$, William A. Rutala PhD, MPH a,b,c \\ a Department of Hospital Epidemiology, University of North Carolina Health Care, Chapel Hill, NC \\ ${ }^{\mathrm{b}}$ Department of Occupational Health, University of North Carolina Health Care, Chapel Hill, NC

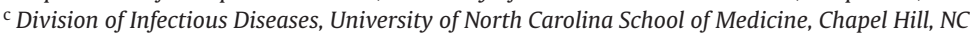

Key Words:

\section{Germicide}

low-level disinfectants

occupational health

risk

asthma

dermatitis

health care personnel

\begin{abstract}
Environmental surfaces have been clearly linked to transmission of key pathogens in health care facilities, including methicillin-resistant Staphylococcus aureus, vancomycin-resistant Enterococcus, Clostridium difficile, norovirus, and multidrug-resistant gram-negative bacilli. For this reason, routine disinfection of environmental surfaces in patient rooms is recommended. In addition, decontamination of shared medical devices between use by different patients is also recommended. Environmental surfaces and noncritical shared medical devices are decontaminated by low-level disinfectants, most commonly phenolics, quaternary ammonium compounds, improved hydrogen peroxides, and hypochlorites. Concern has been raised that the use of germicides by health care personnel may increase the risk of these persons for developing respiratory illnesses (principally asthma) and contact dermatitis. Our data demonstrate that dermatitis and respiratory symptoms (eg, asthma) as a result of chemical exposures, including low-level disinfectants, are exceedingly rare. Unprotected exposures to high-level disinfectants may cause dermatitis and respiratory symptoms. Engineering controls (eg, closed containers, adequate ventilation) and the use of personal protective equipment (eg, gloves) should be used to minimize exposure to high-level disinfectants. The scientific evidence does not support that the use of low-level disinfectants by health care personnel is an important risk for the development of asthma or contact dermatitis.
\end{abstract}

Health care-associated infections (HAIs) remain an important source of patient morbidity and mortality. Based on a large prevalence study, it was estimated that 722,000 HAIs occurred in U.S. acute care hospitals in 2011, leading to approximately 75,000 deaths. ${ }^{1}$ Key interventions for reducing HAIs have included the following: appropriate hand hygiene by health care personnel (HCP), use of new technologies to reduce device-related infections (eg, antisepticimpregnated central venous catheters), strict adherence to asepsis while inserting or maintaining invasive devices, prompt recognition and isolation of patients with communicable diseases, and use of germicides for disinfection of medical instruments and surface disinfection.

\footnotetext{
* Address correspondence to David J. Weber, MD, MPH, 2163 Bioinformatics, CB \#7030, Chapel Hill, NC 27599-7030.

E-mail address: dweber@unch.unc.edu (D.J. Weber).

Funding/Support: Supported by the University of North Carolina at Chapel Hill. Publication of this article was supported by an educational grant from Clorox Healthcare, Sealed Air, and Tru-D. Content of this article was initiated and written by the authors with no input or financial support to the authors from Clorox Healthcare, Sealed Air, or Tru-D.

Conflicts of Interest: Drs Rutala and Weber are consultants to Clorox.
}

The use of germicides in health care continues to be based on the scheme devised $>45$ years ago by Spaulding. ${ }^{2-5}$ Spaulding believed that the nature of disinfection could be understood more readily if instruments and items for patient care were divided into 3 categories based on the degree of risk of infection involved in the use of the items. The 3 categories he described were critical (enters sterile tissue and must be sterile), semicritical (contacts mucous membranes and requires high-level disinfection), and noncritical (comes in contact with intact skin and requires low-level disinfection).

Critical items are so-called because of the high risk of infection if such an item is contaminated with any microorganism, including bacterial spores. Therefore, it is critical that objects that enter sterile tissue or the vascular system be sterile because any microbial contamination could result in disease transmission. This category includes surgical instruments, cardiac and urinary catheters, implants, and ultrasound probes used in sterile body cavities. The items in this category should be purchased as sterile or be sterilized by steam sterilization if possible. If heat sensitive, the object may be sterilized by a variety of low-temperature methods. Semicritical items are those that come in contact with mucous membranes or nonintact skin. Respiratory therapy and anesthesia equipment, 
Table 1

Self-reported injuries or illnesses caused by exposure of chemicals, including germicides, 2003-2012

\begin{tabular}{|c|c|c|c|c|c|c|}
\hline \multirow[b]{2}{*}{ Condition } & \multicolumn{5}{|c|}{ Reported Exposures (N) } & \multirow[b]{2}{*}{ Total* } \\
\hline & Antiseptic & $\begin{array}{l}\text { Sterilants and high-level } \\
\text { disinfectants }\end{array}$ & $\begin{array}{c}\text { Low-level } \\
\text { disinfectants }\end{array}$ & Miscellaneous & $\begin{array}{l}\text { Unknown or } \\
\text { not specified }\end{array}$ & \\
\hline Exposure evaluation (no exposure because of PPE) & & & & & & $33(4.77)$ \\
\hline Dermatitis & 11 & 4 & 6 & 2 & 17 & $40(5.79)$ \\
\hline Splash to mucous membranes & 5 & 7 & 15 & 3 & 0 & $30(4.34)$ \\
\hline Inflammation (heat, swelling, redness) & 1 & 8 & 0 & 0 & 1 & $10(1.45)$ \\
\hline Chemical exposure & 0 & 6 & 1 & 2 & 0 & $9(1.30)$ \\
\hline Chemical burn & 1 & 2 & 1 & 1 & 1 & $6(0.69)$ \\
\hline Total* & $18(2.61)$ & $27(3.91)$ & $23(3.33)$ & $8(1.16)$ & $19(2.75)$ & \\
\hline
\end{tabular}

$P P E$, personal protective equipment.

*Values in parenthesis are per 10,000 work years.

gastrointestinal endoscopes, cystoscopes, bronchoscopes, laryngoscopes, esophageal manometry probes, anorectal manometry catheters, endocavitary probes, prostate biopsy probes, infrared coagulation devices, and diaphragm fitting rings are included in this category. These medical devices should be free of all microorganisms (ie, mycobacteria, fungi, viruses, bacteria); however, small numbers of bacterial spores may be present. Intact mucous membranes, such as those of the lungs or gastrointestinal tract, generally are resistant to infection by common bacterial spores but susceptible to other organisms, such as bacteria, mycobacteria, and viruses. Semicritical items minimally require high-level disinfection using high-level disinfectants or chemical sterilants cleared by the Food and Drug Administration. Noncritical items are those that come in contact with intact skin but not mucous membranes. Intact skin acts as an effective barrier to most microorganisms; therefore, the sterility of items coming in contact with intact skin is not critical. Examples of noncritical items include devices such as bedpans, blood pressure cuffs and crutches and environmental surfaces in rooms, such as bed rails, bedside tables, toilet seats, and patient furniture. In recent years, there has been a growing appreciation that the contaminated surface environment is an important source of pathogens that may colonize or infect patients. For this reason, environmental surfaces in patient rooms are routinely disinfected (eg, once per day) and disinfected when the patient is discharged from their room (ie, terminal disinfection).

In general, critical and semicritical items are sterilized or disinfected in a central processing area or in a limited number of locations within a health care facility. High-level disinfectants include glutaraldehyde, ortho-phthalaldehyde, and peracetic acid. The health risk associated with the use of germicides for sterilization or highlevel disinfection has been reviewed. ${ }^{6}$ In contrast, noncritical devices and environmental surfaces are routine disinfected throughout the hospital. For this reason, this article will review the literature to assess the risk(s), if any, to HCP posed by the use of germicides with a focus on low-level disinfection of noncritical patient equipment and environmental surfaces. Common chemicals used for lowlevel disinfection include phenolics, quaternary ammonium compounds, chlorine-based products, and improved hydrogen peroxides. ${ }^{5}$ In addition to low-level disinfectants, HCP will also routinely be exposed to agents used for hand hygiene, most commonly waterless alcohol-based products and $2 \%-4 \%$ chlorhexidine. ${ }^{7}$ They may also be exposed to less commonly used hand hygiene agents, including chloroxylenol, hexachlorophene, iodine and iodophors, quaternary ammonium compounds, and triclosan. ${ }^{7}$ Finally, low-level disinfectants and hand antiseptics may be available over-thecounter for use in homes.

The major disorders attributed to the use of germicides by HCP have been respiratory diseases (eg, asthma) and cutaneous disorder (eg, contact dermatitis).

\section{REVIEW OF SELF-REPORTED INJURIES OR ILLNESSES ASSOCIATED WITH CHEMICAL EXPOSURE}

The University of North Carolina Hospitals assesses HCP employed by the health care system in their occupational health clinic. This clinic, which is conveniently located, is staffed by 2 part-time physicians, 1 full-time family nurse practitioner, and 2 full-time nurses. A review of all HCP seen for injuries or illnesses related to chemical exposures was undertaken for the years 2003-2012.

\section{Methods}

The electronic medical records of the occupational health clinic were searched for key words such as chemical, dermatitis, germicide, and antiseptic. A line listing was prepared of all HCP with a possible chemical exposure. The medical charts were then reviewed and abstracted. Only incident cases were ascertained.

The number of full-time equivalent HCP was obtained from human resources.

\section{Results}

Over the time period studied, 2003-2012, UNC Hospitals employed 69,075 full-time work years, which constituted 144 million person days of exposure. Injuries or illnesses caused by chemical exposures were very uncommon (Table 1). Overall, 70 of 128 chemical exposures were caused by a known germicide (ie, antiseptic, high-level disinfectant, low-level disinfectant), including alcohol 17, quaternary ammonium compound 18 , germicide (not specified) 12 , glutaraldehyde 7 , peracetic acid 6 , hypochlorite (bleach) 5 , phenol 3 , and chlorhexidine 2. Other chemicals included floor strippers, cleaning agents, formaldehyde, xylene, toilet cleaners, and miscellaneous.

Staff often reported exposure events, but no injury was present because the HCP were wearing appropriate personal protective equipment $(\mathrm{N}=33)$. Dermatitis was the most common complaint, but the incidence of dermatitis was only 5.79 per 10,000 work years. Dermatitis was most commonly a result of exposure to antiseptics. However, many HCP were unable to link a specific chemical to their dermatitis. Splashes to mucous membranes were the next most common exposure. These most often involved exposure to a low-level disinfectant. Importantly, no episodes of acute bronchospasm or persistent asthma were reported related to germicide exposure. Overall, 19 injuries involved splashes to the eye.

Although low-level disinfectants are used by most HCP, more injuries and illnesses resulted from exposure to high-level disinfectants than low-level disinfectants. High-level disinfectants and sterilants involved in exposures included glutaraldehyde 6, 
ortho-phthalaldehyde 2 , and ethylene oxide 1 . Formaldehyde was involved in 18 exposures.

\section{Comments}

Overall, the incidence of injury or illness as a result of chemical exposure was exceedingly rare. With regard to injuries or illnesses caused by germicides, splashes were mostly commonly reported, followed by dermatitis. Although uncommon based on incidence, splashes to the eye were an occasional reason for a visit to occupational health, emphasizing the need for health care providers to use eye protection when using germicides. In general, ascertainment should be excellent despite the fact that our data were based on self-reports because the cost of most injuries or illnesses would have been covered by Worker's Compensation. Additionally, the occupational health clinic is located within the facility, the clinic takes walk-ins with a minimal wait, and all services are provided at no cost to the health care providers.

Theoretical limitations of our data with regard to dermatitis include the following. First, there may be a under ascertainment of dermatitis for the following reasons: (1) per hospital policy, any health care provider with nonintact skin on or below the wrists or on or above the neck was placed off work until the lesions healed; and (2) under North Carolina Worker's Compensation law, chemical sensitization (which would include chemical-induced dermatitis) is not compensable. Therefore, any health care provider placed off work would need to use their sick leave, vacation time, or apply for leave. However, no supervisor has ever indicated that a health care provider declined care in occupational health for one of these reasons. Second, no testing was obtained to validate a self-reported link between dermatitis and chemical exposure (ie, testing of specific chemical sensitization by patch tests or IgE levels). As previously noted, many HCP were unable to link a specific chemical with their dermatitis.

\section{REVIEW OF THE LITERATURE ASSESSING WHETHER LOW- LEVEL DISINFECTANTS ARE AN OCCUPATIONAL HAZARD}

\section{Respiratory hazard risks}

Assessing the risk of low-level disinfectant exposure by HCP for precipitating respiratory symptoms or disease (principally asthma) in HCP has a number of methodologic challenges. First, the asthma is one of the most common diseases in the world and has a rising prevalence. ${ }^{8}$ Further, $>50$ risk factors have been associated with the development of childhood asthma. ${ }^{8}$ Second, HCP are exposed to multiple different chemicals in health care facilities, including lowlevel disinfectants, antiseptics, inhaled and topical medications, natural rubber products, sensitizing metals, and lotions and creams. Third, the degree and frequency of exposure to the various chemicals to which HCP are exposed are difficult to assess. Fourth, products used in health care have changed over time. For example, latexinduced asthma should be uncommon these days in U.S. hospitals because the use of latex gloves is now a rarity. Many studies of respiratory hazards in HCP have failed to quantitatively assess the frequency and degree of exposure to various chemicals, use an appropriate comparative population because diseases such as asthma are common in the general public, and validate questionnaire data with objective medical tests (ie, pulmonary function tests, bronchial challenge).

Several articles have reviewed the risk of asthma in cleaning workers. ${ }^{9-12}$ Most studies included in these reviews have reported an increased risk of asthma in cleaning workers related to level of exposure to cleaning products, cleaning sprays, bleach, ammonia, and mixing products. Importantly, few articles included in these reviews validated self-reported asthma, there was no specific review of asthma in $\mathrm{HCP}$, and the use of protective equipment (eg, gloves) was not assessed.

Wiszniewska and Walusiak-Skorupa reviewed respiratory hazards in HCP. ${ }^{13}$ Among the studies they referenced were articles by Loborde-Casterot, ${ }^{14}$ Gonzalez, ${ }^{15}$ Arif, ${ }^{16}$ Walters, and colleagues. ${ }^{17}$ The study by Laborde-Casterot et al assessed patients, not HCP. ${ }^{14}$ The study by Gonzalez et al used a cross-sectional design and reported that nurses had a higher rate of physician-diagnosed asthma than administrative staff, which was associated with manual mixing of quaternary ammonium compounds. ${ }^{15}$ Importantly, the study demonstrated no increased risk for asthma among cleaners and no significant difference in specific IgE levels to quaternary ammonium compounds among those exposed and not exposed to quaternary ammonium compounds. Arif and Delcols assessed the association of asthma and work in a health care facility via a populationbased survey. ${ }^{16}$ The only chemical associated with occupational asthma in a multinomial regression analysis was chloramines, which are not used as low-level disinfectants. Many chemicals were significantly related to work-related asthma, including bleach, room cleaners-abrasives, and cleaners for restrooms, detergents, ammonia, glutaraldehyde, formaldehyde, chloramines, and ethylene oxide. Limitations of this study included the lack of a comparator group and no medical testing to validate the subjects' reported symptoms. The study by Walters et al reviewed reports of occupational asthma reported to the Midland Thoracic Society's Surveillance Scheme of Occupational Asthma from 1991-2011. ${ }^{17}$ Overall, there were 125 reports of which the most commonly reported inciting chemicals were glutaraldehyde $(n=69)$, latex $(n=47)$, and cleaning products $(\mathrm{n}=27)$. Limitations of the study included that the reporting system was voluntary, incidence rates were not available, and there was no medical testing to validate self-reports.

Dumas et al assessed the relationship between asthma and exposure to cleaning products in hospital workers. ${ }^{18}$ No association was observed between cleaning and disinfecting tasks and current asthma in men or in women whatever the assessment method used. Using a cross-sectional population study, Mirabelli et al found no association between HCP-reported asthma and disinfection use. ${ }^{19}$ They did report an increased risk of asthma among those that used ammonia or bleach. However, because they used a combined category of ammonia and bleach, they were unable to assess whether bleach use was related to asthma. This is important because ammonia is not used as a low-level disinfectant on environmental surfaces.

In conclusion, the currently available data do not demonstrate that the use of germicides, including low-level disinfectants in hospitals, is associated with occupational asthma in HCP.

\section{Dermatitis or eczema risks}

Dermatitis or eczema caused by use of latex gloves and hand hygiene antiseptics (eg, chlorhexidine) is well described in the medical literature. ${ }^{20,21}$ The prevalence of latex allergies in HCP has decreased with the increasing use of non-natural rubber products, gloves with reduced content on natural rubber, and nonpowdered gloves. ${ }^{20}$

There is only limited data on the frequency of dermatitis in HCP because of exposures to low-level disinfectants. Ibler et al used a self-administered questionnaire to assess hand eczema in 3,183 HCP and reported that there was no difference in the use of disinfectants between responders with and without hand eczema. ${ }^{22}$ Machovcova et al reviewed the Czech National Registry of Occupational Diseases from 1997-2009. ${ }^{23}$ HCP with dermatitis most commonly linked their illness to high-level disinfectants (ie, glutaraldehyde, formaldehyde). Only $12 \%$ linked their illness to use of cleaning agents. Limitations of the study include the inability to 
determine incident rates of disease and lack of validation of the selfreported illnesses.

In conclusion, there are scant data linking dermatitis or eczema in HCP to the use of low-level disinfectants. If fact, the available data suggest that the use of low-level disinfectants rarely would lead to dermatitis or eczema.

\section{Conclusions}

The data reviewed in this article suggest that the routine use of low-level disinfectants by HCP is rarely associated with clinically significant illness. A recent article reviewed the literature regarding potential health effects of exposures to low-level disinfectants. ${ }^{24}$ Many of the articles cited were case reports or case series. Many of the other articles had design flaws as previously noted, such as failure to describe incidence, assess controls, confirm data acquired by questionnaires, and perform objective tests to assess disease. However, this article did provide excellence guidance on current gaps in knowledge, research, and practice regarding the use of low-level disinfectants in health care.

\section{HAZARDS ASSOCIATED WITH THE USE OF HIGH-LEVEL DISINFECTANTS}

High-level disinfectants are widely used in health care to chemically disinfect reusable, semicritical medical (eg, endoscopes), and dental devices. Current Food and Drug Administration-approved high-level disinfectants contain one of the following active ingredients: glutaraldehyde, ortho-phthalaldehyde, peracetic acid, hydrogen peroxide, hydrogen peroxide-peracetic acid, or hypochlorous acid-hypochlorite (bleach). ${ }^{5}$ Formaldehyde, which is commonly used in health care as a fixative agent, will also be discussed. Although there is some literature on potential adverse occupational health because of use of glutaraldehyde (see subsequent discussion), there is little published about potential occupational health risks of high-level disinfectants more recently cleared by the Food and Drug Administration (ie, orthophthalaldehyde, peracetic acid, hydrogen peroxide, hydrogen peroxide-peracetic acid). ${ }^{25}$

A recent Web-based survey of 4,657 health care professionals (ie, nurses, technologists and technicians) reported that most commonly used high-level disinfectants in the last week were glutaraldehyde (59\%), peracetic acid (16\%), ortho-phthalaldehyde (15\%), hydrogen peroxide (8\%), and hydrogen peroxide plus peracetic acid (2\%). ${ }^{25}$ Importantly, examples of work practices or events that could increase exposure risk included the failure to wear waterresistant gowns (44\%), absence of standard procedures for minimizing exposures (19\%), lack of safe handling training (17\%), failure to wear protective gloves (9\%), and spill or leak of highlevel disinfectants while handling (5\%).

\section{Glutaraldehyde}

Glutaraldehyde is a low molecular weight aliphatic dialdehyde, with 2 active carbonyl groups. Glutaraldehyde has a pungent odor with a threshold recognition value of $0.04 \mathrm{ppm}$ by volume in air. In the hospital glutaraldehyde is used primarily as a chemical sterilant or high-level disinfectant for temperature-sensitive medical instruments that cannot be steam sterilized, such as endoscopes. ${ }^{26}$ It can also be used as tissue fixative, embalming fluid, an adhesive in dentistry, and as a preservative in some cosmetic, toiletry, and household cleaning agents.

Glutaraldehyde exposure in hospitals has been linked to eye irritation, skin rash, rhinorrhea, headache, cough, and shortness of breath. Most commonly glutaraldehyde exposure has been linked to dermatitis ${ }^{27-33}$ and asthma. ${ }^{27-30,33,34}$ However, these studies often had design flaws, including lack of a control population, failure to comprehensively measure glutaraldehyde exposure levels, and failure to control for potential confounders.

Glutaraldehyde is particularly irritating to mucous membranes, including the conjunctiva, pharynx, and gastrointestinal tract. Most cases of severe human toxicity via direct contact have been reported in patients after the use of medical instruments immersed in glutaraldehyde with inadequate rinsing. Toxicity in HCP has been reported much less commonly.

Occupational exposure to glutaraldehyde vapor has been reported to result in mucous membrane irritation and pulmonary symptoms, including lacrimation, skin irritation, rhinorrhea, upper respiratory tract irritation, cough, and epistaxis. Occasionally asthma has been noted in exposed health care providers.

Glutaraldehyde should be stored or used in tightly sealed containers. Closed disinfection systems (eg, automatic endoscope reprocessors) may be used. It should be used in well-ventilated rooms. Health care providers with contact dermatitis, chronic occupational asthma, or other symptoms which may be related to glutaraldehyde exposure should be evaluated by occupational health.

A permissible exposure limit has not been established by the Occupational Safety and Health Administration (OSHA), but the National Institute for Occupational Safety and Health (NIOSH) has suggested a recommended exposure limit of $0.2 \mathrm{ppm} .{ }^{35}$

\section{Formaldehyde}

Formaldehyde (formalin) is used in hospitals as a tissue fixative in autopsy rooms and surgical suites. Formaldehyde is a hazardous chemical; airborne concentrations of 0.5-2.0 ppm may cause irritation of the eyes, nose, throat, and respiratory tract in some individuals. ${ }^{6}$ Occupational exposure in hospitals should be reduced by product substitution, engineering controls, respirators, protective clothing, work practice changes, and exposure monitoring. The NIOSH has suggested a limit of $0.75 \mathrm{ppm}$ time-weighted average and 2 ppm short-term exposure limit. ${ }^{36}$

\section{Peracetic acid}

Peracetic acid is a strong oxidizer that is produced from the acidcatalyzed reaction between acetic acid and hydrogen peroxide. ${ }^{37}$ Animal studies have demonstrated that peracetic acid can produce strong local effects on direct contact to the eyes, skin, and respiratory tract. Pechacek et al after a review of the literature concluded that "the available data for PA frequency come from unpublished studies that lack sufficient study details, suffer from gaps in available information and often follow unconventional testing methodology. ${ }^{37}$ Nevertheless, environmental controls (eg, sealed chambers, appropriate ventilation, use of personal protective equipment [eg, gloves]) should be used to minimize exposures. OSHA has not recommended specific exposure limits for peracetic acid.

\section{Ortho-phthalaldehyde}

Ortho-phthalaldehyde is an aromatic dialdehyde. ${ }^{38}$ Compared with glutaraldehyde, OPA has several advantages: it does not require activation, it has excellent stability, and has a barely perceptible odor.

Ortho-phthalaldehyde stains proteins gray and therefore will also stain unprotected skin. It must therefore be handled using appropriate personal protective equipment (ie, gloves, eye protection, fluidresistant gowns). Patients instrumented with devices disinfected with ortho-phthalaldehyde have developed anaphylaxis (ie, urticarial, angioedema, laryngeal edema, loss of consciousness, chest tightness, convulsions). ${ }^{38}$ These reactions have been felt to occur because of 
a lack of adequate rinsing of the disinfected device. Occasional cases of occupational asthma or dermatitis have been reported in HCP as ascertained by questionnaires. ${ }^{38}$ The OSHA has not published specific exposure limits for ortho-phthalaldehyde.

\section{CONCLUSIONS}

Concern has been raised that use of germicides by HCP may increase the risk of these persons for developing respiratory illnesses (principally asthma) and contact dermatitis. Our data demonstrate that dermatitis and respiratory symptoms (eg, asthma) as a result of chemical exposures, including low-level disinfectants, are exceedingly rare. Unprotected exposures to high-level disinfectants may cause dermatitis and respiratory symptoms. Engineering controls (eg, closed containers, adequate ventilation) and use of personal protective equipment (eg, gloves) should be used to minimize exposure to high-level disinfectants. The scientific evidence does not support that the use of low-level disinfectants by HCP is an important risk for the development of asthma or contact dermatitis.

\section{References}

1. Magill SS, Edwards JR, Bamberg W, Beldavs ZG, Dumyati G, Kainer MA, et al Multistate point-prevalence survey of health care-associated infections. N Engl J Med 2014;370:1198-208.

2. Rutala WA, Weber DJ. Disinfection and sterilization in health care facilities: what clinicians need to know. Clin Infect Dis 2004;39:702-9.

3. Rutala WA, Weber DJ. Sterilization, high-level disinfection, and environmental cleaning. Infect Dis Clin North Am 2011;25:45-76.

4. Rutala WA, Weber DJ. Disinfection and sterilization: an overview. Am J Infect Control 2013;41:S2-5.

5. Rutala WA, Weber DJ. Disinfection, sterilization and antisepsis: an overview. Am J Infect Control 2016;44:e1-6.

6. Weber DJ, Rutala WA. Occupational risks associated with the use of selected disinfectants and sterilants. In: Rutala WA, editor. Disinfection, sterilization and antisepsis in health care. Washington DC: Association for Professionals in Infection Control and Epidemiology, Inc.; 1998. p. 211-26.

7. Centers for Disease Control and Prevention. Guideline for hand hygiene in health-care settings: recommendations of the Healthcare Infection Control Practices Advisory Committee and the HICPAC/SHEA/APIC/ADSA Hand Hygiene Task Force. MMWR Morb Mortal Wkly Rep 2002;51:1-45.

8. Beasley R, Semprini A, Mitchell EA. Risk factors for asthma: is prevention possible? Lancet 2015;386:1075-85.

9. Zock J-P, Vizcaya D, Le Moual N. Update on asthma and cleaners. Curr Opin Allergy Clin Immunol 2010;10:114-20.

10. Quirce S, Barranco P. Cleaning agents and asthma. J Investig Allergol Clin Immunol 2010;20:542-50

11. Siracusa A, de Blay F, Folletti I, Moscato G, Olivieri M, Quirce S, et al. Asthma and exposure to cleaning products-a European Academy of Allergy and Clinical Immunology task force consensus statement. Allergy 2013;68:1532-45.

12. Folletti I, Zock J-P, Moscato G, Siracusa A. Asthma and rhinitis in cleaning workers: a systematic review of epidemiological studies. J Asthma 2014;51:18-28.

13. Wiszniewska M, Walusiak-Skorupa J. Occupational allergy: respiratory hazards in healthcare workers. Curr Opin Allergy Clin Immunol 2014;14:113-8.

14. Loborde-Casterot H, Villa AF, Rosenberg N, Dupont P, Lee HM, Garnier R. Occupational rhinitis and asthma due to EDTA-containing detergents or disinfectants. Am J Ind Med 2012;55:677-82.
15. Gonzalez M, Jegu J, Kopferschmitt M-C, Donnay C, Hedelin G, Matzinger F, et al. Asthma among workers in healthcare settings: role of disinfection with quaternary ammonium compounds. Clin Exp Allergy 2013;44:393-406.

16. Arif AA, Delclos GL. Association between cleaning-related chemicals and work-related asthma and asthma symptoms among healthcare professionals. Occup Environ Med 2012;69:35-40.

17. Walters GI, Moore VC, McGrath EE, Burge PS, Henneberger PK. Agents and trends in health care workers' occupational asthma. Occup Med (Lond) 2013;63:513-6.

18. Dumas O, Donnay C, Heederik DJJ, Héry M, Choudat D, Kauffmann F, et al. Occupational exposure to cleaning products and asthma in hospital workers. Occup Environ Med 2012;69:883-9.

19. Mirabelli MC, Zock J-P, Plana E, Antó JM, Benke G, Blanc PD, et al. Occupational risk factors for asthma among nurses and related healthcare professionals in an international study. Occup Environ Med 2007;64:474-9.

20. Reunala T, Alenius H, Turjanmaa K, Palosuo T. Latex allergy and skin. Curr Opin Allergy Immunol 2004;4:397-401.

21. Larson E, Girard R, Pessoa-Silva C, Boyce J, Donaldson L, Pittet D. Skin reactions related to hand hygiene and selection of hand hygiene products. Am J Infect Control 2006;34:627-35.

22. Ibler KS, Jemec GBE, Agner T. Exposures related to hand eczema: a study of healthcare workers. Contact Dermatitis 2012;66:247-53.

23. Machovcova A, Fenclova Z, Pelclova D. Occupational skin disease in Czech healthcare workers from 1997 to 2009. Int Arch Occup Environ Health 2013;86:289-94.

24. Quinn MM, Henneberger PK, National Institute for Occupational Safety and Health (NIOSH), National Occupational Research Agenda (NORA) Cleaning and Disinfecting in Healthcare Working Group, Braum B, Delclos GL, et al. Cleaning and disinfecting environmental surfaces in health care: towards an integrated framework for infection and occupational illness prevention. Am J Infect Control 2015;43:424-34.

25. Henn SA, Boiano JM, Steege AL. Precautionary practices of healthcare workers who disinfect medical and dental devices using high-level disinfectants. Infect Control Hosp Epidemiol 2015;36:180-5.

26. Beauchamp RO, St. Clair MBG, Fennell TR, Clarke DO, Morgan KT. A critical review of the toxicology of glutaraldehyde. Crit Rev Toxicol 1992;22:143-74.

27. Norback D. Skin and respiratory symptoms from exposure to alkaline glutaraldehyde in medical services. Scand J Work Environ Health 1988;14:366-71.

28. Vyas A, Pickering CAC, Oldham LA, Francis HC, Fletcher AM, Merrett T, et al Survey of symptoms, respiratory function, and immunology and their relation to glutaraldehyde and other occupational exposures among endoscope nursing staff. Occup Environ Med 2000;57:752-9.

29. Waldron HA. Glutaraldehyde allergy in hospital workers. Lancet 1992;339:880

30. Calder LM, Wright LP, Grimstone D. Glutaraldehyde allergy in endoscopy units. Lancet 1992;339:433.

31. Bardazzi F, Melino M, Alagna G, Veronesi S. Glutaraldehyde dermatitis in nurses. Contact Dermatitis 1986;14:319-20.

32. Fowler JF. Allergic contact dermatitis from glutaraldehyde exposure. J Occup Med 1989;31:852-3.

33. Dimich-Ward H, Wymer ML, Chan-Yeung M. Respiratory health survey of respiratory therapists. Chest 2004;126:1048-53.

34. Gannon PFG, Bright P, Campbell M, O'Hickey SP, Burge PS. Occupational asthma due to glutaraldehyde and formaldehyde in endoscopy and x ray departments. Thorax 1995;50:156-9.

35. Occupational Safety and Health Administration. Glutaraldehyde. Available from: https://www.osha.gov/dts/chemicalsampling/data/CH_243400.html. Accessed November 10, 2015.

36. The National Institute for Occupational Safety and Health (NIOSH). Formaldehyde. Available from: http://www.cdc.gov/niosh/idlh/50000.html. Accessed November $10,2015$.

37. Pechacek N, Osorio M, Caudill J, Peterson B. Evaluation of the toxicity data for peracetic acid in deriving occupational exposure limits: a mini review. Toxicol Lett 2015;233:45-57.

38. Pala G, Moscato G. Allergy to ortho-phthalaldehyde in the healthcare setting: advice for clinicians. Expert Rev Clin Immunol 2013;9:227-34. 